\title{
The Space Produce in Chinatown of Bangkok
}

\author{
Kaiwan Xiong ${ }^{1, \text { a }}$ \\ ${ }^{1}$ Social Management College Kunming university Kunming city Yunnan province of China \\ afengchu452@163.com,
}

Keywords: Spaces Produce, Culture communication. Interaction, Chinatown of Bangkok

\begin{abstract}
This study presents an anthropological study which used qualitative methods to uncover the relationship between the spaces produce and culture communication in Chinatown of Bangkok. In this study, the community of Chinese in Yaowa Rat Road was taken as the field of ethnic culture communication. I will begin with the space produce as a site of social interaction between different ethnic groups over memory, meaning and the construction of collective consciousness. It then question how these culture communication between different ethnic group played out, playing particular attention to the real work of creating, recreating and maintaining the community and ethnicity identity.
\end{abstract}

\section{Introduction}

In history, The south China and Southeast Asia have had culture communication for a long time. Actually, there are many natural links in this region. Great rivers originating from southwest of China flow through mainland southeast of Asia, most importantly the Salween, the Red River, and the great system of the Mekong, rising in south China and follows through most of countries on southeast peninsula last to the South China Sea. These are the traffic arteries link southwest of China to the countries on the southeast peninsula. For thousands of years, the peoples who live this area have developing the communication, cooperation, trade, tourism, pilgrimage and scientific exchanges frequently.

Many Chinese migrated to Southeast Asia including what is now Thailand. In the thirteenth century A.D., Chinese traders began setting up societies in Thailand's early trading towns at and near Sukhothai during the Sukhothai period (1279 - 1438 A.D.). During the Rattanakosin (Bangkok) period (1782 A.D.), especially in the King Rama I period (1782-1809 A.D.), many Chinese immigrants settled in Bangkok. The Chinese received permission from the King to relocate their community in the Yaowara area. It is there today and is still called the Chinatown of Thailand. The majority of the Chinese immigrants came to Thailand following the end of the Second World War (1945), since there were no restrictions on immigration at that time.

The majority of Chinese settle in Bangkok come from three provinces in South china named Canton, Fukien, and Hainan. These three provinces contain heterogeneous speech group, most of them are also found in Bangkok. Different dialects, different culture traits, and diversity in religious beliefs and practice are to be found among the various ethnic groups in south China. Teochius, Hakkas, and Hokkiens, Gontonese and Hainanese are predominant in Bangkok. Their diversity background reflected in their different forms of economic and social adaptation. In another hand, when all of them living together and interaction with the Thai in Bangkok, the social interaction may reflect the process of the ethnic culture communication between South China and Thailand in some extent.

This study presents an anthropological study which used qualitative methods to uncover the relationship between the spaces produce and culture communication in Chinatown of Bangkok. In this study, the community of Chinese in Yaowa Rat Road was taken as the field of ethnic culture communication. I will begin with the space produce as a site of social interaction between different ethnic groups over memory, meaning and the construction of collective consciousness. 


\section{The physical Space Production in Yaowa Rat}

As Lefebvre pointed out early, the space practices would be the physical and representation spaces of community territory, from the borders, fences, walls and barriers erected to mark its external limits, to the creation and maintenance of large scale infrastructure enabling flows of people, goods, energy and information[1]. The process of space production of Chinese community in Sampeng have going on a long time with the process of ethnic culture communication as well. The physical space production and culture communication The physical space conclude of row-house pattern, road, represent buildings, public space. The produce of physical space takes very important influence on culture communication. In Chinese shop-house community, the member usually was the relatives and the companions, from the same area of in China. These people optically has the same skills, engage in similar business, in some case, one has the opportunity to learn the skill while living together, consequently, the community formed into district of particular products service, such as jewels, golden shop, shoe maker, tailor, and so on, this commercial district are still in existence in many parts of the city and have inspired the new shopping center development in Bangkok. For example, the place on the south east of Sampeng name Siang Kong, approximately in 1871, corresponding to the reign of Chulalongkorn, a group of Chinese immigration from Hokkian territory come to settle at this place in Bangkok originally, the settlement was located on a canal and it was developed into an area for trade of used engines, this is the first junkyard business in Thailand, known as Siang Kong (see figure1 No.9). Any of several similar or related examples is the watch and clock shops, the golden shops, and restaurants in Yaowa Rat road.

The most important social action for Chinese lived or living in Sampeng to produce the physical space is to build Chinese temples and road. The Yaowa Rat road is one of the 18 new roads in the project to promote the trading business centering in Sampheng District which was submitted for approval from king Rama V by the Ministry of Public Works, Yaowarat Road was first constructed in 1892 in the area originally densely populated by the Chinese. The community had been in poor surroundings amidst numerous badly littered. Dirty and untidy-looking alley-ways situated between Charoen Krung(new road) and Sampheng roads. The construction of took altogether eight years, to comply with the exiting cluster of houses. It was also following his initiation that rows of modern shop-houses were built along the road for rent to traders, thereby opening up an opportunity for a great number of Chinese to start their own businesses. In some extent, the Chinatown was related to the Yaowa Rat road. The important thing is most of Chinese attributed the built of Yaowa Rat Road to the king:

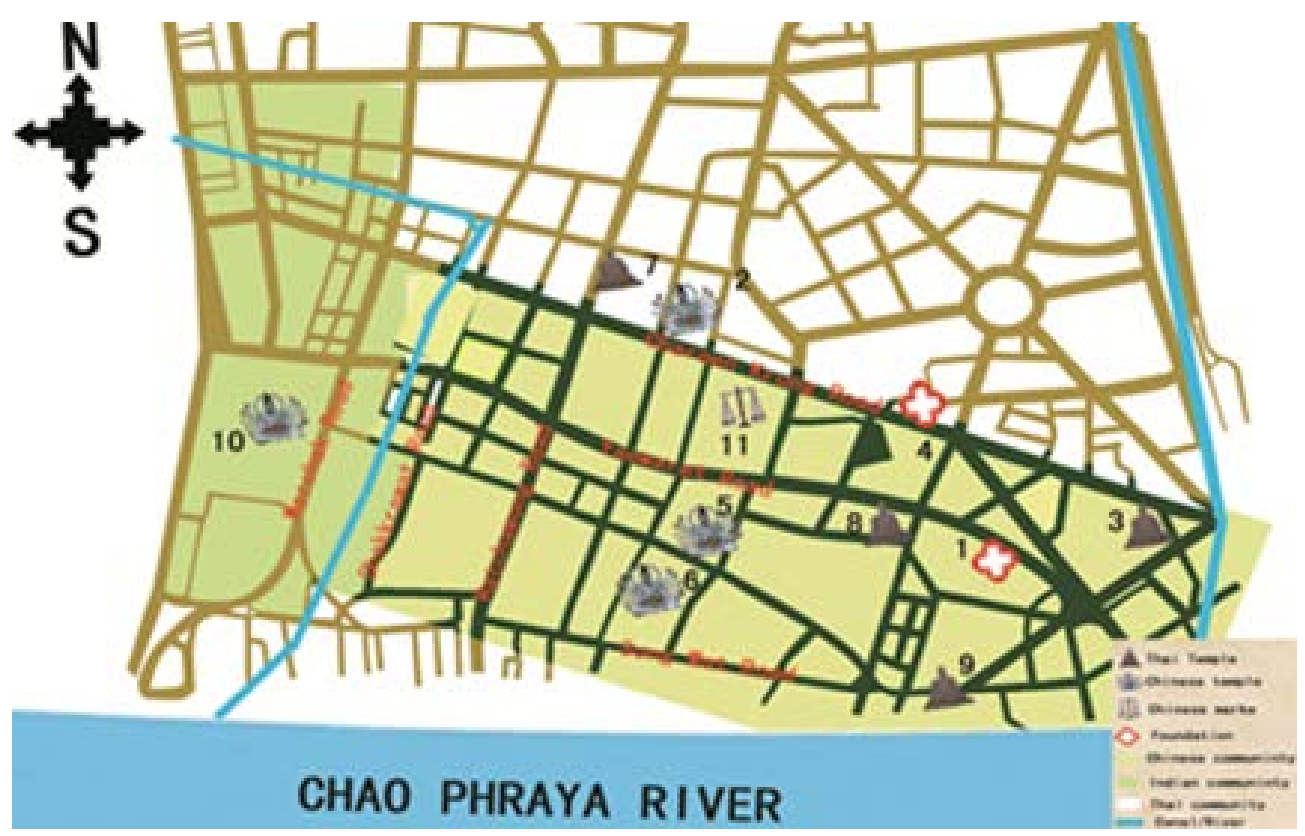

Figure1. a map for Yaowa Rat Chinese community 
Here we have origins and origins in common, every things has its original source and primary ancestor, the moral feature that make us human, that it drinking water and remember the source, our common source is the person who put the first brick in this place, that is the king. If we remember our common origins sink into oblivion, and are lost, and then our work is not complete (interview, No.1).

When the road was first built there was a high concentration of Chinese in the area, it was the trading center for quality goods and was the location of the tallest building in Bangkok then, at present, Yaowa Rat Road still retains much of its business supremacy and it is here that Sino-Thai extraction carry on with their traditional way of life.

As the settlement growth in population, different people would begin to settle the area that won't possess that same kind of religious belief. The settlement must achieve with an identity of the ethnicity, and they created an institutionalized religion that lends credibility to the leadership and cohesion to the rest of the society, a key tool of religion for maintaining the legitimacy was the building of representation architecture. To build the Chinese temple become the key way to maintain the culture character as well as the legitimacy foundation of culture communication[2]. Someone have point out that, "a map showing the distribution of Chinese in Thailand can also be a map of the distribution of Chinese temple." Firstly, the emergence of the Chinese temples is an important symbol which is the formation of the Chinese community in the region. It shows that the Chinese people have the intention to get married and begin a career in the locality. There is no a Chinese temple is built by virtue of the power of one or two persons, It was built to depend upon the strength of the groups who make contribution, in this sense, where is a Chinese temple, where is a community of Chinese people gathering. In addition, we can find many Chinese temples in Thailand is built by the association of fellow provincials, In other words, the religious culture represented by the temples have combined with the ethnic culture represented by the clansmen association organically from the beginning, in the Chinese community of Thailand.

In any case, Most of Chinese temples are representative for the South China people's values and beliefs. At the same time, because of the establishment in a foreign country, there is no doubt that the Chinese temples are blending with the local culture. AT last, there will be a phenomenon that Thai and Chinese temple borrow the style of architecture from each other. It was very obvious when we observe the pattern of the temples in Chinatown and the near. There is a TianHou shrine in Mea wat Lial, Sam Por Kong in Wat Kanlayanamit Woramahawihan, A shrine of Kuan Yim in Wat kanman Tuyaram... it not only means Chinese do their best to produce the representation space for their community, but also, it a result of the ethnic culture communication as well as the culture integration.

In the past I lived in side, which was called Chinese field, this Gong Wu shrine has been here for a long time. When I was a boy, my grandfather told me that the shrine was built already here when he come out from china, in the past the shrine was built of wood with a roof made out of Nipa palm thatch. It has been change many times, Thuat thong is a Muslim, he come from chaozhou, he was a junk trade, he built this pavilion (sala) here as a rest place for the travelers, latter, the Chinese especially those who live in Chinese field, who felt grateful for this pavilion, came to restore it changing it into a wooden building, it was rebuilt many times, finally, they built the concrete building that you see today. In the past, when the Chinese migrated here they use to organize a festival every year. It was great fun. My grandfather was a Teochiu who had come out from China. My grandmother was a Thai; my grandfather was a head man in the Chinese field village. When Chinese out from China, he would help them to find place to live and to hunt to make a living, in my grandfather's and father's time, there are a lot of Chinese in this place, and in my grandfather's time when my father was young, he told me that the Chinese who had come from China come along near canal (Klong)(interview, No.2)

This case from local history of Yaowa Rat Chinese community demonstrates that wherever Chinese come to settle they would to erect sprit shrines, this is a way of expressing respect to the local sprits of the area, without consideration of what nationality they were, it is a Chinese custom 
to pay respect to those who are virtuous, it shows an attempt to overcome difference among person of different nationalities in order to live peacefully together.

Wat Leng Nei Yi (see figure1, No.2) is a Zen Buddhist temple here; it was built in Chinese architectural style with the Waving tiles roof, decorated with animal and floral design stuccos. The principal Buddha image is gold colored of religious rites. Inside the Wiharn (sermon hall), the images of Thao Chatulokaban (the four guardians of the world) in Chinese warrior costumes are installed. There are many statues of saints of the local Chinese belief. On the rear of the temple, there are 3 pavilions one of Kuan Yim, one of the temple founders, and one of Lak Chow Saint. The faithful people believe that coming to pay homage to all the saints in the temple will bring the good lucks in various aspects of life, such as healthy, business and family life. to some extent, the spirit of Zen and Confucian, both of which have become something of trademark for Chinese's business success, Again, both in the Chinese ethnic group and in Thai this culture communication embody both cross-culture assimilation and a persistence of ancient belief, the assimilation clearly a two-way street, Buddhist spirit such as Karma, coming from china culture, have had an enormous impact on Thai spiritual ideas.

\section{The Production of Representation Space in Yaowa Rat Road}

Representation space involves how group perceive and conceive physical and social space. The representation of space is produce or reproduced through various discourse, including the culture integration and persistence. They are determined by ideology of ethnic group, local knowledge, and the tradition value system among the ethnic groups which take part in the space produce. By the perspective of Lefebvre, the production of representation space is more important than the physical space[3]. In some extent, this construction of space is the space of everyday practice, livelihood of commercial exchange and ritual of merit making in dairy life, social organization life.

If we take Chinese community in Yaowa Rat as a whole, we can found that Chinese in this place propensity for social grouping manifests itself by a complex pattern of formal association which characterizes the community at this level. There are hundreds of associations grouping together individual with similar family, economic and religious interests. In their totality, they direct the life of who community. We can teak Kwong Siew association as an example.

Kwong Siew association (see the figure1, No.4) also named Kwong Siew god temple or Kwong Siew hospital, As know from a stone inscription in the temple, in early times, the Chinese come from South China belong to different group and confliction with self-interest.

From the history of Kwong Siew association and the stone inscription in Kwong Siew hospital, we can conclude that at least four functions were support the production of space for the ethnicity culture communication. Firstly, it is an agency of social control to combat disorder, social unrest and open conflict among their numbers. Secondly, it can enforce the social solidarity; it can also provide new comers some supports when they are feeling helpless as an unassimilated status. Thirdly, the association also has welfare functions to serve the special needs or aspiration of Chinese population, providing social security programs for the poor and patients. And finally, the association exercise diplomatic functions vis-à-vis other groups even the government of Thailand to protect the interests of Chinese. Above all, in some extent, the association supports the function of produce of the public sphere in the Chinese community.

It is meaningful to talk about the relationship between the association and God temple here. In Yaowa Rat Chinese community, the association mostly link with the God temple. And the Chinese God temple is often taken as public temple of Chinese in Thailand. They talk serious things in the public temple and do merit in it. In some extent, practice of the belief and association within community remain clearly Chinese in organization and style. A key relationship between community and God temple is thus merit making focus on family members, but such a relationship not only connects individual to the place but established important horizontal links binding the community together. For key ceremonies, such as ordination, merit is general make in public. In addition, cremations and the social activities preceding and concluding the activity demand a great deal of preparation. It is here where neighbors and friends honor obligation and assist in activities ranging from food preparation to origin music and entertainment. The ceremonies attract a wide 
range of social groups near of community and there is little in the way of social exclusive. In this way, some Chinese style arts were spread in the process of ritual, for examples, Chaozhou opera, Chaozhou folk music, and finally, the unique Chaozhou cuisine. The Chaozhou people developed the use of the Kongfu tea drinking custom as a social and cultural activity that includes the discussion of politics, family, and social topics including music. We can see there is much news about Chaozhou opera performancein Chinese festival or activity in merit making.

Chinese religion allowed for the expression of local distinctive, while maintaining a degree of uniformity, particularly in the performance of ritual, that linked local practice to a system of general significance with Chinese culture.

In Thailand, where the indigenous cosmological landscape is crowded with powerful entities and where Theravada Buddhism is closely identified with, and promoted by the state, Chinese religious practice would seem especially susceptible to diversification. Skinner once pointed out that Buddhism have played a significant role in the assimilation of Chinese to Thai society[4]. later, Keyes characterized Theravada Buddhism as an 'open' religion, accessible to those with allegiances to other creeds and images[5], and later, some scholars such as Tobias have suggested the similarities between Mahayana Buddhism of Chinese and Thai Buddhism have made the acceptance of the Thai religion among immigrant Chinese and their decedents easier.

The proposition that religious ritual and initiations help define ethnic identity and maintain group solidarity is widely accepted by many scholars. A community constitutes the basic ritual and moral entity that grounds a Chinese's sense of belonging. When different group of people live together in Chinatown collectively, the reason why new religious practices become wants is that not only search a new order of things for the people, but also expanded the "self" into an imagined community that extends across ethnicity boundaries.

Among the communities of Chinese in Thailand, it is possible to treat religious life and practice as skin to a prism through which to view the way that new social expectation are worked out in symbolic ways. We have already seen something of the ways that household have responded to economic change and environment transformation in the long and short time. We can view this as expression of identity and status which affection the configuration of the local landscape in the context of wide social and economic change in Thai society. Religious life in the close-knit local societies of Yaowat Rat road has also contribute to transformation in the environment, for while in the ritual context it continues to affirm local based identity and networks, it also draws on influence and symbols which promote new distinctions between people and communities. However, while ethnic group employ rituals and initiations to sustain group identity and solidarity, the effectiveness of this strategy depends on the interplay of a variety of factors; social, economic, political circumstances, difference within the ethnic group and how the rituals and initiations are "reinvented". As regards the role of sprit worship as an important factor for the integration of Chinese society, the Lao Pun Tao Kong shrine (town pillar) must be considered the most important of all. The present building of the shrine was made by Chinese and decorated with Chinese pattern and symbols. Even the altar is Chinese-type altar. The Chinese descended living in Sampeng, business people in Yaowat Road worship the Lao Pun Tao Kong shrine. In China there have always been the custom of having town pillar and the guardian sprit of the town, when Chinese come to Sempeng, they must have come to worship of the Lao Pun Tao Kong shrine, thus the Lao Pun Tao Kong shrine has a Chinese placard saying 'old Pun Tao Kong shrine”, and another one which says that this Shrine at this location for a very long time. The present mayor, who has Chinese ancestors, says that the local Chinese call the shrine "Ping Dao" and that the shrine is worship by the Sino-Thai people as well as by some Thai people.

\section{Result and Discussion: The Boundary and Chance for Culture Communication}

Due to geographical location and security reason, Thais in center region, in the past, enjoyed their water ways life style. Dwelling in river or Klong-side house and craft, shopping at a floating market, travelling to anywhere, school, city temple all by boat, were the way of everyday live. However, only in some remote area in Bangkok, in these days, people maintain this kind of life style and even enjoying the life. As agrarian society, Thai cultivate their own food and produce their 
own necessities. They exchange their surplus products among themselves and only a few special goods can provide to the foreigners. This can be the fundamental factor that Thais are not active in any commerce and service. It was not until last century that Thai elites have become interested in foreign trade and fabrication products. In the other hand, traditionally, there was the spatial separation between Thais and others. the people who live in same klong is considered as relatives because people from this klong are the same group of people, the foreign merchants, the captives from the prior were the alien were allocated to settle outside of city wall. As for possible the security reason, each ethnic group habitually resided around the city as small communities.

With the increasing of the culture communication, more and more people found that a good neighbor is an even better fence than the real one, the roads were built and the wall was put down. Chinese are well accepted into Thai society from sharing similar attitude of living and believing of the same religious. So after Chinese and Thai communities have merged together during the urban growth, some shop-houses were built in the same compound of Thai residence, more specially, the fringe area along the road, in this case, Chinese benefit from their business and Thai earn extra income from the rent and still maintain the peace at the home behind the shop-houses wall, and gradually, some of the Thais take part in the process of business of Chinese and run themselves business finally.

Barth, whose emphasis is on understanding of ethnic group, sates that boundaries persist despite the flow of personal across them[6], rather, difference are created across boundaries through such interaction. From the business relationship, marriage between Thai and Chinese, and the integration of religion, we often find that the new boundary was building with the old boundary was dismissed.

I consider religion to be a special form of culture communication which brings awareness and negotiation of the boundaries. My field work in Chinatown confirmed that Chinese descendants routinely had some involvement in Thai Buddhism. Much of this activity was center around concern for ancestors. People told me that they often went to Thai temples on ancestral death anniversaries or at the tomb clear day (Qing Ming) to ask the monks to performance merit-making for the dead.

In the self-view of the Thai, Thai ethnicity is most often defined in linguistic and culture terms: a Thai is a person who speak a Thai without accent and who lives in a Thai urban and rural style of life[7]. This kind of identity is open up to all ethnic groups living in Thailand, and take over the history of culture communication between south of China and Thailand, we can found the boundaries were also broken down with the culture integration, just as an inscription in Tian Fa foundation(seethe figure1,No.1)demonstration:

Thailand is not far away from some places of China, such as Yunnan, Guangdong, Guangxi and other places, although it is one of countries located aside South Sea, relationship with China is like a family because of the history. Therefore, a lot of Chinese people especially who living in travel in this place, Tian Fa Hospital to build up here is in line with the demand for health and longevity of Chinese people living in local. Therefore, because of the increase in people's demand for health care and more people from near and far to see the doctor, we'd better not to lose or hide the purpose of saving lives.

In Zen wisdom, there is an old saying that "the way of Buddha is no more than a means of livelihood, calling on the name of the Buddha Amitabha is any more than a means to keep the stomach filled". this inscription, the wants of healthy, happy life, was attached much importance, and the boundary of ethnicity in mental and in physics become no important less, the distant with geography and culture become meaningless, a spirit of public is emerge and become the strongest power to integrate the difference.

I have described the ethnic culture communication at the family level, community level and the boundary which was produced within the process of culture communication. It not only provides a demonstration of the life style and social relationship of Chinese who living in Thailand and with a South China culture background, but also gives out a pattern of cross-culture communication.

By all accounts, the Chinese community in Yaowa Rat is a bounded entity, limited both in size and in its social and ritual characteristic. In both contemporary practices, we can find there is a stability continuity dynamics of flexible adaption and culture openness against the ethnicity boundary when we compare Chinese community across the space and time. The key to understand 
this dual tendency seem to lie in the tense conflict relationship between the action and social structure in the process of space production.

Stepping further from approaching community in the aspect of its meaning, we can take it as an ethos building upon the time and space. The sociologist has described the spirit of a community as tolerance, reciprocity, and trust. Matt Ridey puts this spirit to the common communication between difference cultures, different races and nations. "humans have social instincts, they come into the world equipped with predisposition to learn how to cooperate, to discriminate the trustworthy from the dishonest, to earn good reputations, to exchange goods and information, and to divide labor...far from being universal feature of animal life, as Kropotkin believed, this instinctive cooperativeness is the very hallmark of humanity and what sets us apart from other animals”[8](Ridley, 1997,).Regardless of the form of community, perhaps this also true for the common culture communication between different culture and nation.

\section{References}

[1] Lefebvre, Henri. The Production of Space[C]. translated by Donald Nicolson-Smith, Oxford: Blackwell 1991.57.

[2] Alan C. Turley. Urban Culture[C].University of New Orleans, Pearson prentice Hall. 2005.44.

[3] Lefebvre, Henri. The Survival of Capitalism: Reproduction of the Relations of Production[C].translated by Frank Bryant, New York: ST. Martin’s press. 1976.102.

[4] Skinner, G.W. Chinese Society in Thailand: an Analytical Study[C].Ithacca: Cornel U. Press. 1957.129.

[5] Keys, Charles F. Ethnic Adaptation and Identity: the Karen in the Thai frontier with Burma[C]. Philadelphia: ISHI. 1979.133.

[6] Barth, Fredrik. Ethnic Groupsand Boundaries [C]. Long Grove, Illionis:Waveland.1969. 134.

[7] Jacques Amyot, the Chinese and the National Integration in Southeast Asia. Institute of Asia Studies Faculty of Political Science Chulalongkorn Unveristy. 1976.84.

[8] Ridey, M.. The Origins of Virtue[C], London: penguin. 1997.36 